\title{
Innovations In Eye Care
}

\author{
Paul Karpecki, OD, FAA0
}

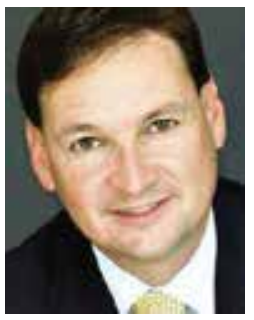

Paul M. Karpecki, OD, FAAO, received his doctor of optometry degree from Indiana University and completed a fellowship in medical cornea and refractive surgery in Kansas City in affiliation with the Pennsylvania College of Optometry. He is director of corneal services and the advanced ocular surface disease clinic at the Kentucky Eye Institute in Lexington, Kentucky.

A noted educator and author, Dr. Karpecki has provided over 1000 invited lectures at various meetings domestically and covering 4 continents. He has also authored over 1000 papers in journals, book chapters, eblasts and newsletters.

He currently serves as the chief clinical editor for Review of Optometry.

$\mathrm{W}$ elcome to the new technology column titled Innovations in Eye Care. The purpose of this column is to educate our profession on the latest and future innovations that could impact our practices and our patients. It is said that approximately 60 $70 \%$ of all patients research medical conditions on the internet before seeing their doctors. Sometimes an internet search could take them in rather unique and interesting directions related to the ocular disease they may have. They will often ask their eye doctors about these technologies and if you can answer their questions on innovative or future technologies, you will likely remain their doctor long-term, since this should instill further confidence in you.

Let's begin with a technology that may have the greatest impact on our patients vision and could treat a number of blinding conditions.

\section{Stem Cell Research}

By definition a stem cell is an undifferentiated cell of a multicellular organism that is capable of giving rise to infinitely more cells of the same type, and from which certain other kinds of cell arise by differentiation. Researchers first discovered ways to derive stem cells from mice embryos in 1981. When it comes to the eye, limbal stem cells have long been known to be the precursor to epithelial cell growth. The ability to harvest these cells in non-controversial ways such as from a cadaver eye (allograft) or pluripotent skin stem cells or from the patients other eye (autograft) are all being studied or currently being applied.

For example damage to corneal epithelial stem cells from trauma including chemical burns or contact lens overwear/inappropriate fit has led to epitheliopathies and persistent epithelial defects known as limbal stem cell deficiency (LSCD). Because the limbal stem cells are critical to epithelial healing, traditional corneal transplants typically fail. By transplanting the damaged limbal areas first, the subsequent corneal transplant is more likely to be successful. Limbal stem cell transplantation (from viable existing cells otherwise cadaver eyes) has led to recovery of stem cells and epithelia healing and recovery in corneas that had previously been opacified. ${ }^{1}$ And the future is even more impressive with potential surrounding pluripotent skin stems cells being programmed as retinal pigment epithelial (RPE) stem cells for the treatment of macular degeneration. ${ }^{2}$ Pluripotent means that the stem cell line can be differentiated into other types of cells, not just the type they originated from. In other words, researchers can take skin stem cells and differentiate them into multiple lines of RPE cells. Although early in progress, the possibilities are life changing. There are companies working on stem cell coated contact lenses that may be used in patients with a history of aniridia who eventually manifest corneal limbal stem cell deficiency, also patients with more severe conditions like Steven's Johnson syndrome, ocular pemphigoid, graft versus host disease $(\mathrm{GVH})$ and even post chemical eye injuries.

Although there are ethical concerns with other forms of stem cells such as embryonic, new research shows that the results presented here suggest that human amniotic fluid may represent a new source for the isolation of stem cells. ${ }^{1}$ In fact an entire line of RPE stem cells is being cultivated from a single source and may be the one source for all patients with AMD in the future.

This knowledge will help patients with longstanding opacified corneas where previous transplants have failed, it will help patients diagnosed with limbal stem cells issues ranging from aniridia and LSCD to the future as a significant treatment for patients suffering from age-related macular degeneration. 


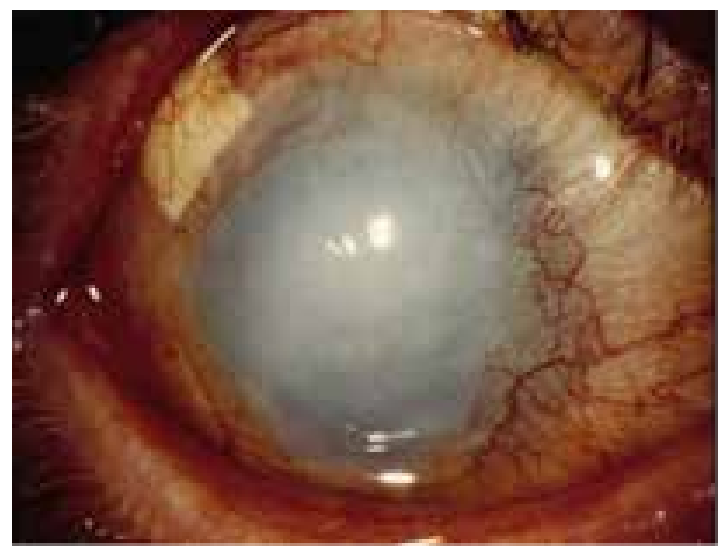

\section{References}

1. Ramachandran C Basu S, Sangwan VS, et al. Concise review: the coming of age of stem cell treatment for corneal surface damage. Stem Cells Transl Med 2014;3(10):1160-8.

2. Kamao H, Mandai M, Okamoto S, et al Characterization of human induced pluripotent stem cell-derived retinal pigment epithelium cell sheets aiming for clinical application. Stem Cell Rep 2014;2(2):205-18.

3. Prusa A-R, Marton E, Rosner M, et al. Oct-4-expressing cells in human amniotic fluid: a new source for stem cell research? Hum Reprod 2003;18(7):1489-93.
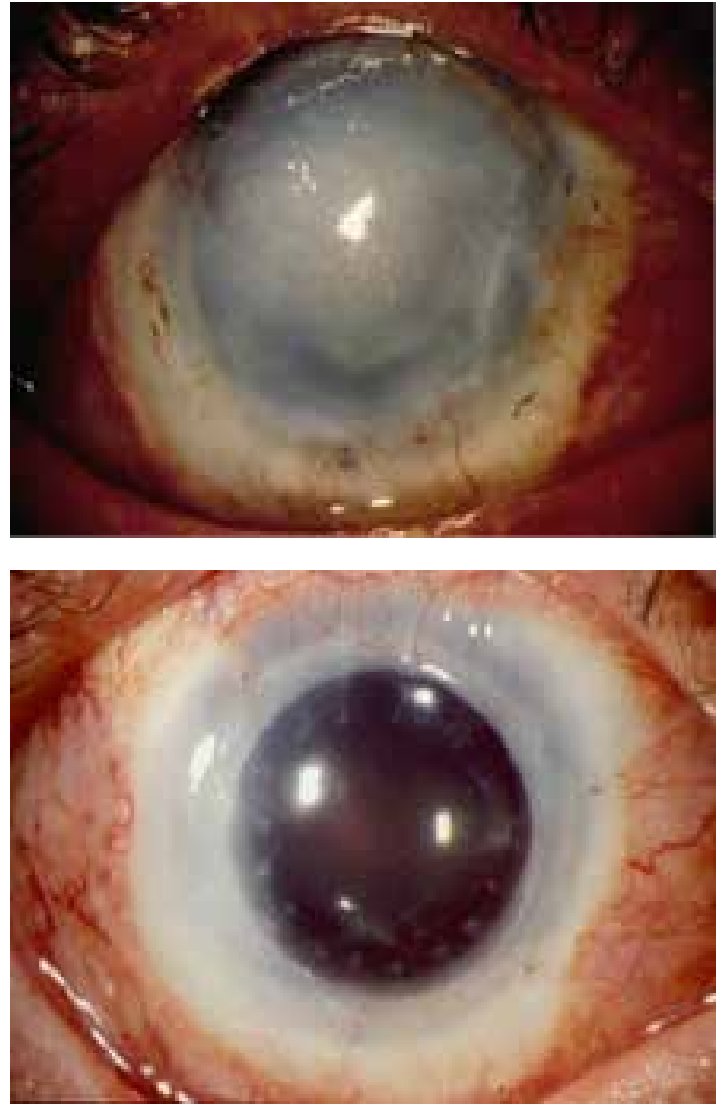

Photos courtesy Edward Holland, MD. 